\title{
Cellular and Matrix Mechanics of Bioartificial Tissues During Continuous Cyclic Stretch
}

\author{
Jeremiah J. Wille, Elliot L. Elson, and Ruth J. OKAmoto \\ Departments of Biomedical Engineering, Biochemistry and Molecular Biophysics and Mechanical and Aerospace Engineering, \\ Washington University, St. Louis, MO
}

(Received 13 January 2006; accepted 6 June 2006; published online: 11 October 2006)

\begin{abstract}
Bioartificial tissues are useful model systems for studying cell and extra-cellular matrix mechanics. These tissues provide a $3 \mathrm{D}$ environment for cells and allow tissue components to be easily modified and quantified. In this study, we fabricated bioartificial tissue rings from a $1 \mathrm{ml}$ solution containing one million cardiac fibroblasts and $1 \mathrm{mg}$ collagen. After 8 days, rings compacted to $<1 \%$ of original volume and cell number increased 2.4 fold. We initiated continuous cyclic stretching of the rings after 2,4 , or 8 days of incubation, while monitoring the tissue forces. Peak tissue force during each cycle decreased rapidly after initiating stretch, followed by further slow decline. We added $2 \mu \mathrm{M}$ Cytochalasin-D to some rings prior to initiation of stretch to determine the force contributed by the matrix. Cell force was estimated by subtracting matrix force from tissue force. After $12 \mathrm{~h}$, matrix force-strain curves were highly nonlinear. Cell force-strain curves were linear during loading and showed hysteresis indicating viscoelastic behavior. Cell stiffness increased with stretching frequency from $0.001-0.25 \mathrm{~Hz}$. Cell stiffness decreased with stretch amplitude $(5-25 \%)$ at $0.1 \mathrm{~Hz}$. The trends in cell stiffness do not fit simple viscoelastic models previously proposed, and suggest possible strain-amplitude related changes during cyclic stretch.
\end{abstract}

Keywords-Tissue engineering, Cell mechanics, Cardiac fibroblasts, Collagen.

\section{INTRODUCTION}

Mechanical stimuli are important for the health and maintenance of many biological functions. ${ }^{14}$ This is especially true in the cardiovascular system where the tissues and organs are undergoing constant cyclic loading. It is the cellular response to these mechanical forces that can either maintain healthy tissue or lead to a pathologic state. ${ }^{1}$

Mechanical stimuli have been used to create more functionally viable engineered tissues. ${ }^{2-5,9,15-17}$ It has been shown that constant amplitude cyclic stretch (a form of mechanical conditioning) of engineered tissue constructs can cause cells to reorient, increase cell proliferation, and

Address correspondence to Ruth J. Okamoto, Department of Mechanical and Aerospace Engineering, Washington University, One Brookings Drive, Campus Box 1185, St. Louis, MO 63130. Electronic mail: rjo@wustl.edu produce more extracellular matrix $(\mathrm{ECM}) .{ }^{3}$ However, these studies generally have looked at how the tissue responds to mechanical conditioning over extended time. ${ }^{9,15}$ In addition, the studies generally quantify the mechanics using only the ultimate strength and modulus ${ }^{4,5,16}$ along with quantification of such biological factors as cell number, gene expression, and ECM components. ${ }^{2,3,17}$

Since it is the cells that actively respond to mechanical loads, it is important to understand the effects of mechanical conditioning on the individual components of the tissue (cell and matrix) and how the mechanical properties change from the time that the conditioning is initiated. Our earlier work has shown that tissue forces drop with subsequent stretches during repeated cyclic stretching. ${ }^{19}$ However, whether this drop occurs in the cells and/or matrix components is not known. Furthermore, it is not known how these drops are affected by different amplitudes and frequencies over many hours of continuous cyclic stretch.

The objective of this study is to measure the short-term $(<24 \mathrm{~h})$ mechanical response of collagen gels populated with cardiac fibroblasts to cyclic stretch at different amplitudes and frequencies. Although engineered tissue constructs may be composed of several cell and matrix components, we chose to use a simple system composed of a single cell type and a single defined ECM component to study the mechanics of tissue components during cyclic stretch. This system provides a 3D environment for the cells while allowing the components to be easily modified and quantified. The benefits of using collagen, the main structural component in cardiovascular tissue, are that its initial concentration can be easily modified and it is more stable than other ECM components such as fibrin. ${ }^{4,5,10}$ By using a single cell type we can avoid complicating effects due to mixed cell populations and clearly understand that cell type's contribution to the tissue mechanics. Cardiac fibroblasts are one of the two main cell types in cardiac tissue and are responsible for ECM maintenance and remodeling. ${ }^{7}$ These cells, along with the cardiac myocytes, undergo continuous cyclic stretch with each heartbeat. Thus, it is 
particularly useful to understand their cellular mechanics during cyclic stretch.

By measuring the cell forces under various cyclic stretch amplitudes and frequencies, we can better understand the relationship between the applied strains and the cells' mechanical response. Then we can model this behavior and be able to predict cellular responses to dynamic physiologic and pathologic loading conditions.

\section{METHODS}

\section{Tissue Ring Fabrication}

Chicken embryonic cardiac fibroblasts (CECF) were isolated from 10 day old chicken embryos (Charles River Laboratories, Wilmington, MA). Cells were maintained in Dulbecco's modified Eagle's medium (DMEM) supplemented with 3\% fetal bovine serum (FBS), 50 units $/ \mathrm{ml}$ penicillin and $50 \mathrm{mg} / \mathrm{ml}$ streptomycin $(\mathrm{P} / \mathrm{S})$. Tissues were fabricated as described previously. ${ }^{20}$ Briefly, CECF from passage 2-8 were added to a collagen solution containing monomeric rat tail tendon collagen (Upstate Biotechnology Inc., Lake Placid, NY) neutralized with $0.1 \mathrm{~N}$ sodium hydroxide $(\mathrm{NaOH})$ and $2 \times$ concentrated DMEM. The final solution contained $1 \mathrm{mg} / \mathrm{ml}$ collagen and one million cells $/ \mathrm{ml}$. Then $1 \mathrm{ml}$ of this solution was poured into cylindrical molds containing an inner mandrel (diameter $=9.55 \mathrm{~mm}$ ). After one hour of incubation, the solution gelled and the molds were filled with incubation medium containing DMEM supplemented with $10 \% \mathrm{FBS}$ and P/S. After five additional hours, the gels were removed from the molds and transferred to spacers (Fig. 1) placed in incubation medium. The spacers consisted of two fixed rods ( $2.07 \mathrm{~mm}$ diameter) separated by a distance to maintain the internal circumference of the rings at $30 \mathrm{~mm}$. Medium was changed every other day.

\section{Mechanical Tests}

After 2, 4, or 8 days of static incubation (Fig. 1) the width of the rings was measured and then the rings were

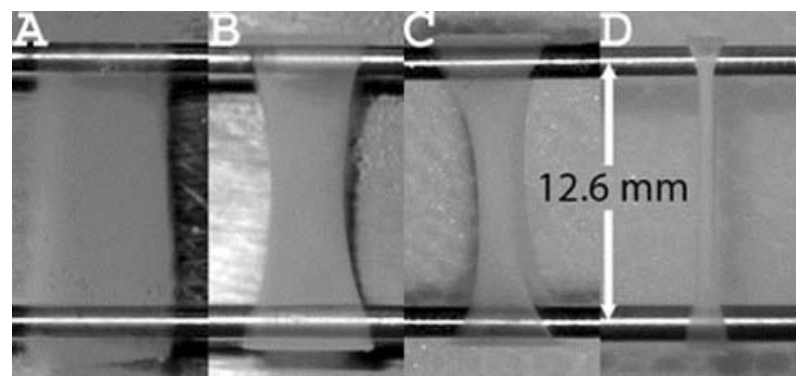

FIGURE 1. Cardiac fibroblast populated rings on spacers during static incubation (A) Day 0 [6 h] (B) Day 2 (C) Day 4 (D) Day 8. Mean ring width was $0.64 \mathrm{~mm}$ after 8 days incubation (see Fig. 4). removed from the spacers. The rings were then mounted on a mechanical tester described previously ${ }^{20}$ that allows independent programmable stretching of four rings while monitoring applied force. The test medium contained DMEM HEPES modification supplemented with $10 \%$ FBS and P/S. All rings were placed on the tester at a baseline length that maintained the inner circumference of $30 \mathrm{~mm}$. This was defined as $0 \%$ strain. In early tests, stretching began immediately after mounting the rings. This led to increases in peak force after initiation of stretch for low amplitudes at early incubation times. Upon further study, it was determined this was a result of the fresh media and FBS used in the test baths and not a result of a mechanical stretch induced response. In all further studies, the rings were mounted on the tester and held at baseline length for $3 \mathrm{~h}$ to allow them to reach equilibrium before testing began.

\section{Effect of Cyclic Stretch Amplitude}

Four rings were tested at each of the three days with each ring stretched either $5 \%, 10 \%, 20 \%$, or $25 \%$ at $0.1 \mathrm{~Hz}$ using a triangular displacement waveform (constant strain rate during loading). The force was continuously monitored at $10 \mathrm{~Hz}$ over $14 \mathrm{~h}$. For many of the figures, the peak force, defined as the maximum force during each cycle, is plotted vs. time (Fig. 2). We use the term stretch to refer to the amplitude of cyclic stretching, while we use the term strain to refer to the amount of deformation at a particular point in the loading curve.

To separate out the individual tissue component forces (cell and matrix), $2 \mu \mathrm{M}$ Cytochalasin $\mathrm{D}$ (CytoD) was added either $3 \mathrm{~h}$ before or $12 \mathrm{~h}$ after initiation of stretch. CytoD disrupts actin filaments inside the cell and thus eliminates the majority of the cell-contributed force. ${ }^{21}$ The remaining force measured 120 min after addition of CytoD is termed the matrix force. Then the estimated cell force is calculated

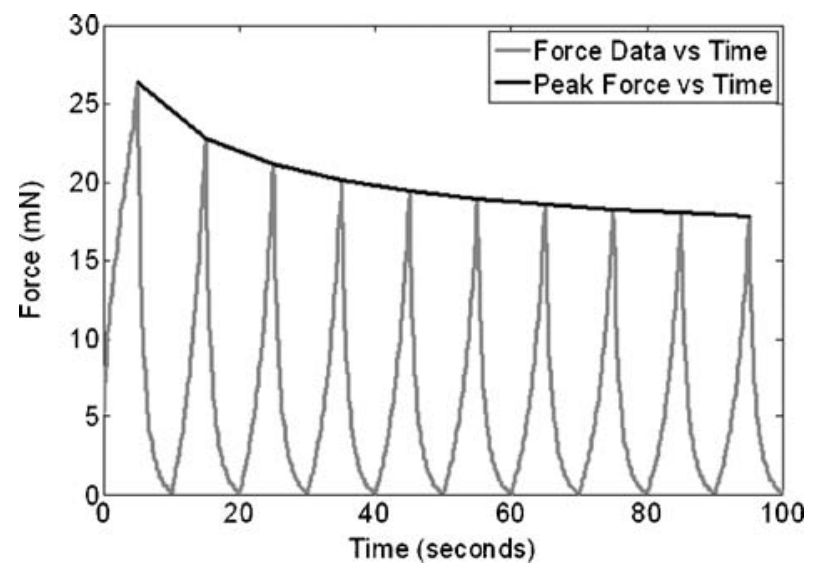

FIGURE 2. Illustration of peak force versus time. The gray curve is sample data obtained for 10 stretch cycles. The black line plots the peak force for each cycle vs. time. This peak force line is used for many of the following figures. 


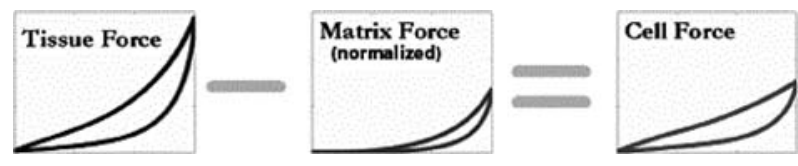

FIGURE 3. Cell force calculation. Matrix force was measured by adding $2 \mu \mathrm{M}$ CytoD to rings prior to initiation of cyclic stretch. Cell force is calculated by taking the normalized matrix force (see Eq. 1) and subtracting it from the tissue force.

by taking the matrix force and subtracting that from the total tissue force without CytoD.

To estimate the cell forces during the initial $12 \mathrm{~h}$ of cyclic stretch, it is necessary to use two separate rings subject to identical stretching protocols. This is accomplished by subtracting the forces measured in a ring with CytoD added prior to cyclic stretching from the forces measured in a ring where CytoD was added after $12 \mathrm{~h}$ of cyclic stretch. We denote these forces $F_{\mathrm{C} 0}(t)$ and $F_{\mathrm{C} 12}(t)$ respectively and similarly, we denote the peak forces $P_{\mathrm{C} 0}(t)$ and $P_{\mathrm{C} 12}(t)$. However, the peak forces after $14 \mathrm{~h}$ of cyclic stretch, when both rings have been treated with CytoD, can still differ between rings subject to identical cyclic stretch protocols due to variations between rings. To account for this variation, we scale the forces in the ring to which CytoD was added before initiating stretch using the following formula:

$$
F_{C 0}^{(s c)}(t)=F_{C 0}(t) \frac{P_{C 12}(14 \mathrm{hr})}{P_{C 0}(14 \mathrm{hr})}
$$

We found that the shape of the loading/unloading curve was similar whether CytoD was added before or after initiation of cyclic stretch. We then subtracted this scaled, or normalized, force curve from the force curve for the ring with CytoD added after $12 \mathrm{~h}$ to obtain an estimated cell force (Fig. 3):

$$
F_{\text {cell }}(t)=F_{C 12}(t)-F_{C O}^{(s c)}(t)
$$

\section{Single Step Stretch and Hold Effect}

To compare the effect of a single stretch to cyclic stretching, a step stretch (stretch to a given stretch magnitude in less than $0.1 \mathrm{~s}$ ) of $5 \%, 10 \%$, or $20 \%$ was applied and the rings were held at this stretched length for $8 \mathrm{~h}$ while the force was monitored. The tissue was then returned to its baseline length and the force was monitored for an additional $6 \mathrm{~h}$. In another set of experiments, CytoD was added $3 \mathrm{~h}$ before or $12 \mathrm{~h}$ after either a $10 \%$ or $20 \%$ step stretch.

\section{Effect of Cyclic Stretch Frequency}

A similar procedure was followed to test frequency effects. Four rings were tested at each of the three days with each ring stretched at either $0.25 \mathrm{~Hz}, 0.1 \mathrm{~Hz}, 0.01 \mathrm{~Hz}$, or
$0.001 \mathrm{~Hz}$ at $10 \%$ stretch amplitude. The current tester's upper frequency limit is $0.25 \mathrm{~Hz}$ and thus unable to stretch at higher frequencies that are closer to physiologic values. CytoD was added either $3 \mathrm{~h}$ before or $12 \mathrm{~h}$ after initiation of stretch to separate out the cell and matrix components as a result of different frequencies of cyclic stretch.

\section{Cell Number}

After the completion of testing, some rings were washed in phosphate buffered saline (PBS) and then placed in $1 \mathrm{ml}$ lysis buffer $(0.1 \%$ sodium dodecyl sulfate (SDS) in PBS). The samples were sonicated until the rings completely disintegrated to release the DNA from the cells. Finally, $30 \mu \mathrm{l}$ of sample was placed in $3 \mathrm{ml}$ of Hoechst working solution (30 nM Hoechst 33258 dye (Sigma, St. Louis, MO) in PBS). The fluorescence was then read by a spectrophotometer and cell number determined from a standard curve obtained from samples with known numbers of cells.

\section{Immunohistochemistry}

Rings were removed from spacers after 2, 4, or 8 days static incubation and immediately placed in a solution of $4 \%$ paraformaldehyde for $30 \mathrm{~min}$, washed with PBS and then permeabilized for $45 \mathrm{~min}$ in $0.2 \%$ Triton $\mathrm{X}-100$ in PBS. This was followed by $1 \mathrm{~h}$ incubation in a blocking solution (2\% normal goat serum and $0.02 \%$ sodium azide in PBS). After blocking, the rings were incubated overnight at $4{ }^{\circ} \mathrm{C}$ in blocking solution containing TRITC phalloidin. Finally, the rings were washed again in PBS and mounted for viewing on a confocal microscope (Zeiss Confocor).

\section{RESULTS}

\section{Ring Width}

Ring width was used as a metric for monitoring the extent of compaction during incubation. The initial width of the rings was approximately $10 \mathrm{~mm}$. This width decreased until day 8 (Fig. 4(b)) when the average width was reduced to $0.64 \mathrm{~mm}$. At this time the cross-sectional area of the ring appeared circular and the volume could be approximately calculated using a circular cross-sectional area and the circumference of the ring. A ring diameter of $0.64 \mathrm{~mm}$ corresponds to a $99 \%$ reduction in the initial tissue volume.

\section{Cell Number}

Rings started with a cell density of one million cells/ml (one million cells per ring). This number increased steadily for 4 days to 2.3 million cells then increased only slightly 

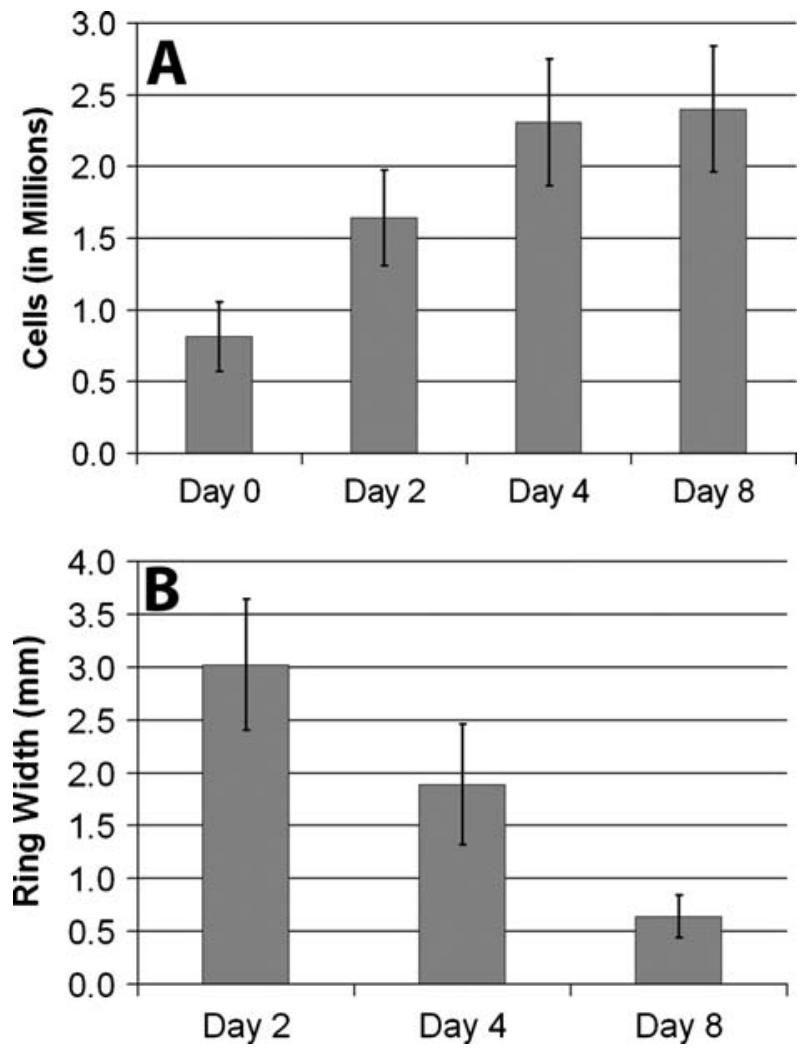

FIGURE 4. Cell number and ring width during static incubation. (A) Cell number increases from the initial 1 million cells to 2.4 million cells after 8 days of static incubation. (B) Ring width decreased from an initial $10 \mathrm{~mm}$ to $0.64 \mathrm{~mm}$ after 8 days of static incubation, with a large amount of compaction occurring prior to day 2.

to day 8 with a total cell number of 2.4 million (Fig. 4(a)). When combined with the $99 \%$ reduction in tissue volume, this translates into a final cell density of 234 million cells $/ \mathrm{ml}$ or a 234 fold increase in cell density.

\section{Amplitude Effect}

The effect of increasing stretch amplitude on the peak tissue and matrix forces is shown in Fig. 5. At all amplitudes, the peak tissue forces immediately after initiating stretch (Fig. 5(a)) increased with static incubation time while the peak matrix forces were similar (Fig. 5(c)). After $12 \mathrm{~h}$ of cyclic stretch, both tissue (Fig. 5(b)) and matrix forces had decreased substantially, with a larger percentage decline in the matrix force (Fig. 5(d)). To examine the relationships between tissue, matrix, and cell forces more closely, figures in the remainder of this paper show data from rings statically incubated for 8 days prior to cyclic stretch unless otherwise noted. Similarities or differences to days 2 and 4 are discussed in the text. In addition, all curves are averages across repeated ( $n=2-7)$ experiments. Due to the large number of different conditions tested and the relatively low number of samples (exact numbers shown in Fig. 5(e), 10(e)) rigorous statistical analysis was not possible.

\section{Tissue Force}

Higher stretch amplitudes resulted in higher initial peak forces (Figs. 5(a), 6(a), 6(b)). With each subsequent stretch, the peak force decreased with large drops during the first several stretches and sustained decreases during the first two hours, but only small further decreases in peak force over the next $10 \mathrm{~h}$ (Fig. 6(a)). In addition, this decrease in peak force was greater at higher stretch amplitudes both in terms of absolute force drop and percentage drop from first stretch. At days 2 and 4, after 12 h of stretch, higher amplitudes still have higher peak forces but the differences were smaller between the amplitudes than the first stretch differences (Fig. 5(a,b)).

By day 8, similar peak tissue forces were seen after $12 \mathrm{~h}$ of cyclic stretch regardless of stretch amplitude between $5 \%$ and $25 \%$ (Figs. 5(b), 6(a), 6(c)). The rings subject to lower stretch amplitudes (5\% or $10 \%$ ) were able maintain a positive baseline force (i.e. force at the baseline, or zero strain, length). At the highest stretch amplitude the rings had periods of zero force during both the loading and unloading of the ring, meaning that at low strains the rings were slack (Fig. 6(c)). After the first stretch (Fig. 6(b)), the loading curve remained nearly linear at $5 \%$ stretch amplitude, but became increasingly nonlinear at higher stretch amplitudes (Fig. 6(c)).

\section{Matrix Force}

Except for the first stretch, the matrix loading curves were nonlinear for all stretch amplitudes tested. Similar to tissue force, higher stretch amplitudes led to higher initial peak forces (Figs. 5(c), 7(b)). For all amplitudes, the peak force decreased with repeated cyclic stretching and this drop in peak force was larger at higher stretch amplitudes (Fig. 7(a)) but higher stretch amplitudes still maintained higher peak forces (Fig. 7(c)). For the first stretch, the ratio of peak forces at day 8 for $25 \%$ to $5 \%$ was $5: 1$, but this ratio decreased to $2: 1$ after $12 \mathrm{~h}$ of stretching, due to the peak matrix force dropping by a greater percentage at the higher amplitudes over time. The other distinct feature was the shape of the loading/unloading curves.

After several hours of stretching the shapes of the loading/unloading curves were very similar for all stretch amplitudes, but the strain value at which the matrix force began increasing from zero during each loading cycle was shifted toward larger strain values. The amount of this shift was greater for higher stretch amplitudes (Fig. 7(c)). This meant that the matrix contributed to the tissue force during the loading only when the strain had reached a value from 3 to $7 \%$ less than its maximum value. This shape and shift is evident at days 2, 4, and 8. For all stretch amplitudes, the matrix is slack at low strains. 


\section{Cell Force}

Cell force increased with increased incubation time. The increase in cell force after $12 \mathrm{~h}$ of stretch from 2 to 4 days of incubation was due to an increase in cell number (per cell force remained the same). However, the increase in cell force from days 4 to 8 could not be explained by the increase in cell number alone, indicating an increase in per cell force. The shape of the first force-strain curve for the cell differed from all subsequent curves. The initial baseline force was followed by a rise and then a leveling off with further increases in force seen only at the higher amplitudes (Fig. 8(b)). During the second stretch, the cell force loading curve was nearly linear. Unlike the tissue and matrix, the cell force loading curve retained a nearly linear shape throughout the $12 \mathrm{~h}$ of cyclic stretch even at $25 \%$ amplitude (Fig. 8(b,c)).

At day 2, the peak cell force initially drops for several cycles, but then gradually increases to the end of the test. The size of the initial force drop is dependent on the stretch amplitude. The trend is similar at day 4, except the cell force at $25 \%$ stretch remains fairly steady instead of increasing. At day 8 , the peak cell force, after the initial drop, increases only for the 5\% and 10\% stretch, while it decreases for the $20 \%$ and $25 \%$ stretch (Fig. 8(a)).
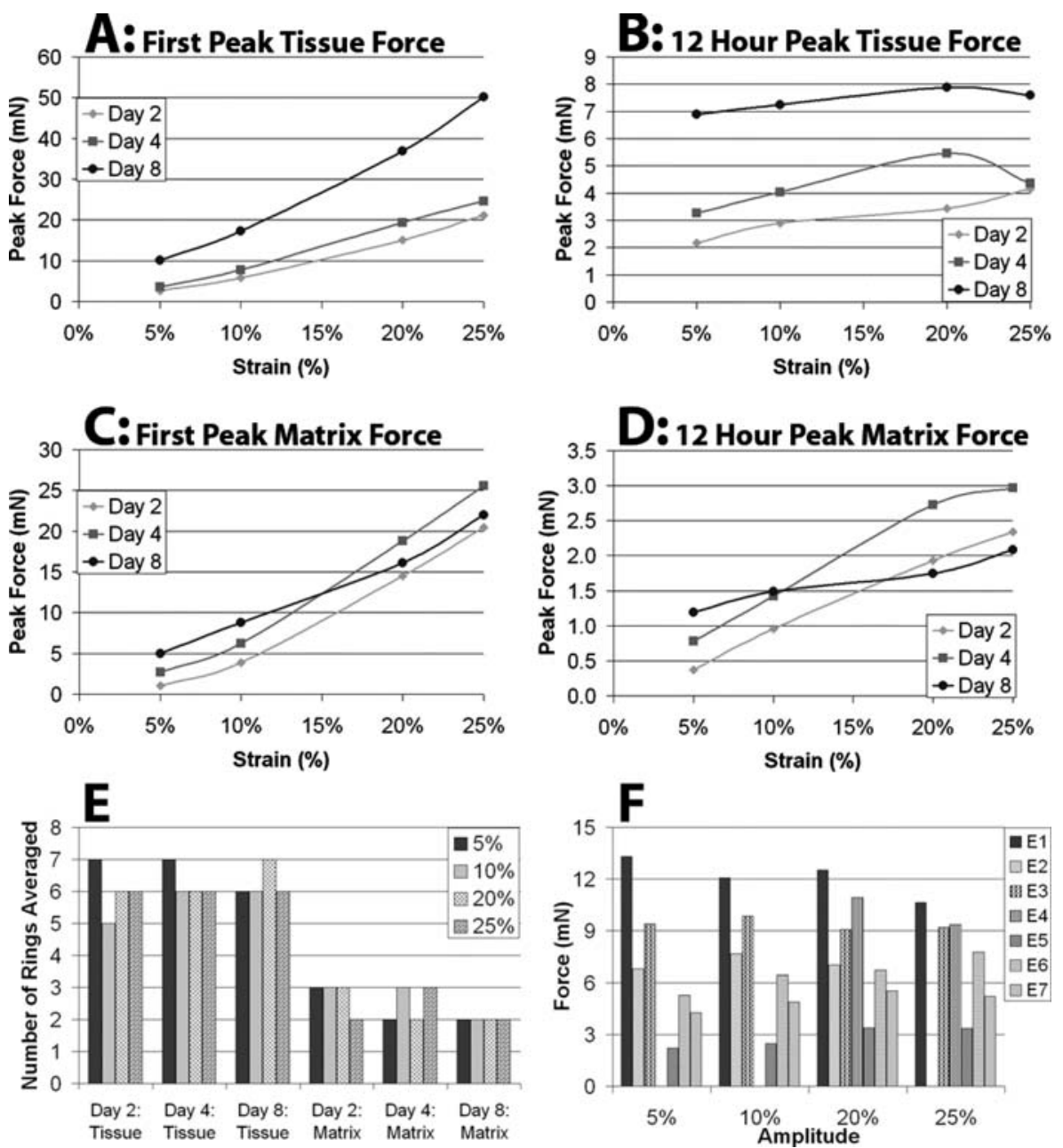

FIGURE 5. Peak tissue and matrix forces for different cyclic stretch amplitudes at $0.1 \mathrm{~Hz}$. (A) Peak tissue force of the first cyclic stretch after 2, 4, or 8 days static incubation. Peak tissue force increases with cyclic stretch amplitude and incubation time. (B) Peak tissue force after $12 \mathrm{~h}$ of cyclic stretch after 2, 4, or 8 days static incubation. At day 8 the peak tissue force is similar regardless of cyclic stretch amplitude. (C) Peak matrix force of the first stretch after 2, 4, or 8 days static incubation. Peak matrix force increases with cyclic stretch amplitude. (D) Peak matrix force after $12 \mathrm{~h}$ of cyclic stretch after 2,4 , or 8 days static incubation. Higher amplitudes result in higher peak forces. (E) Number of rings averaged for data shown in Figures 5-8 at each amplitude and static incubation day. (F) Individual measurements used in panel B [Peak tissue force after 12 h, 8 days of incubation]. This shows that the trend within an experiment, i.e. rings fabricated on a single day, is consistent but the experiment to experiment variation in forces is large. Y-axis scales are different in each panel to emphasize the trends with amplitude and incubation time. 

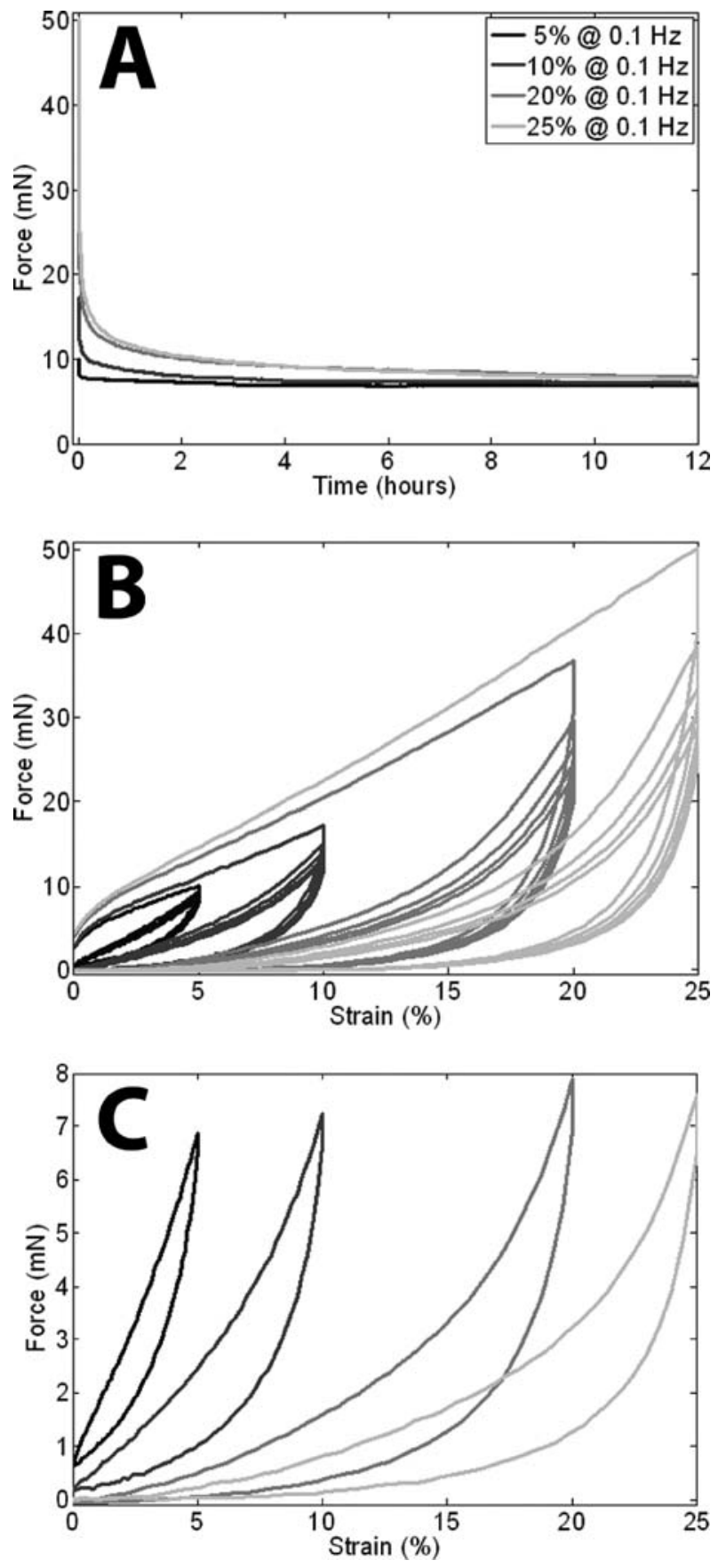

FIGURE 6. Tissue force versus cyclic stretch amplitude after 8 days of static incubation. (A) Peak tissue force over $12 \mathrm{~h}$ of cyclic stretch. Peak tissue force dropped quickly after initiation of cyclic stretch followed by a continued slow decline. (B) First 5 tissue stretches after initiation of cyclic stretch. A large decline in tissue force and hysteresis occurred between the first and second stretch. (C) Last 5 tissue stretches after $12 \mathrm{~h}$ of cyclic stretch. The peak tissue force is similar at the four amplitudes.
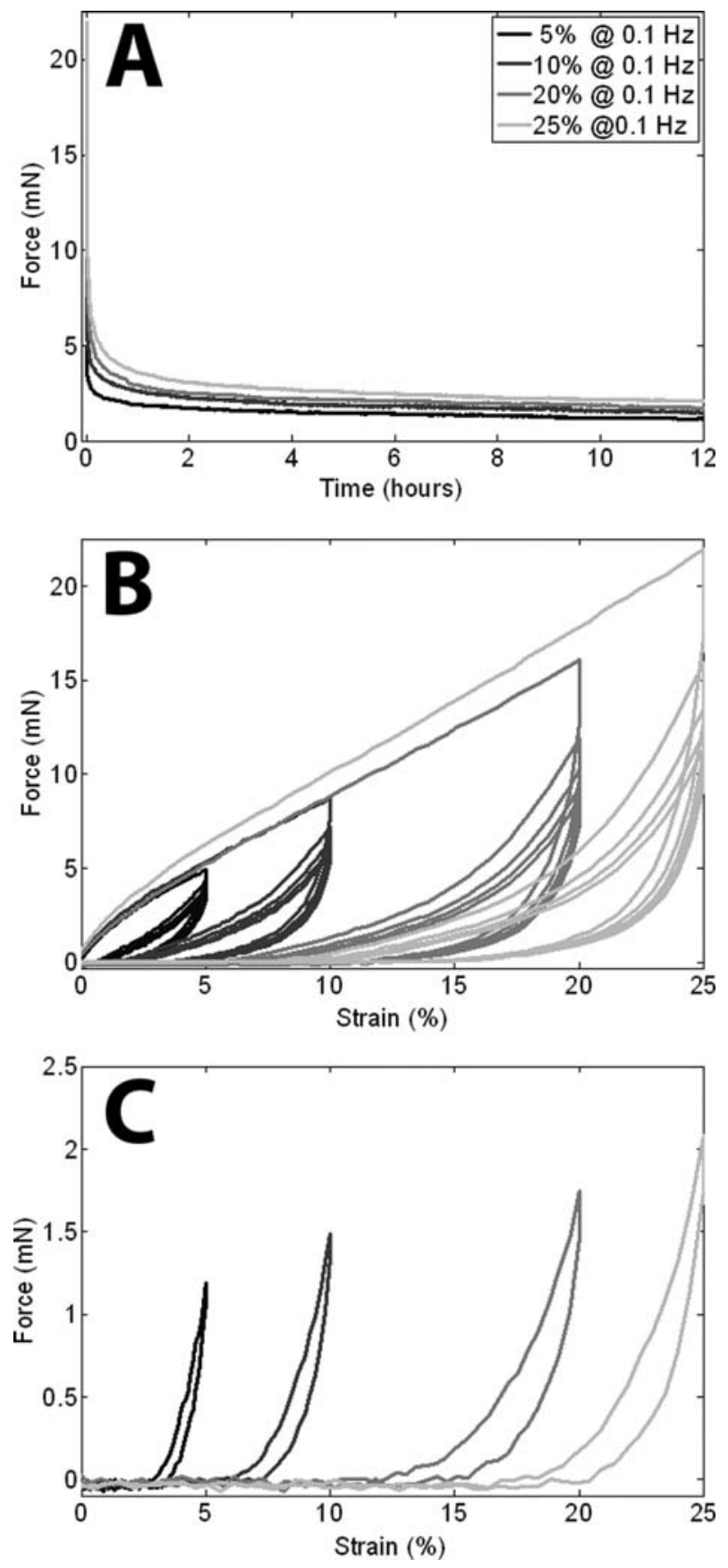

FIGURE 7. Matrix force versus cyclic stretch amplitudes after 8 days of static incubation. (A) Peak matrix force over $12 \mathrm{~h}$ of cyclic stretch. Peak matrix force dropped quickly after initiation of cyclic stretch followed by a slow decline for the $12 \mathrm{~h}$ duration. (B) First 5 matrix stretches after initiation of cyclic stretch. A large decline in matrix force and hysteresis occurred between the first and second stretch. (C) Last 5 matrix stretches after $12 \mathrm{~h}$ of cyclic stretch. Matrix loading curve is highly nonlinear and peak force increased slightly with higher cyclic stretch amplitude. 

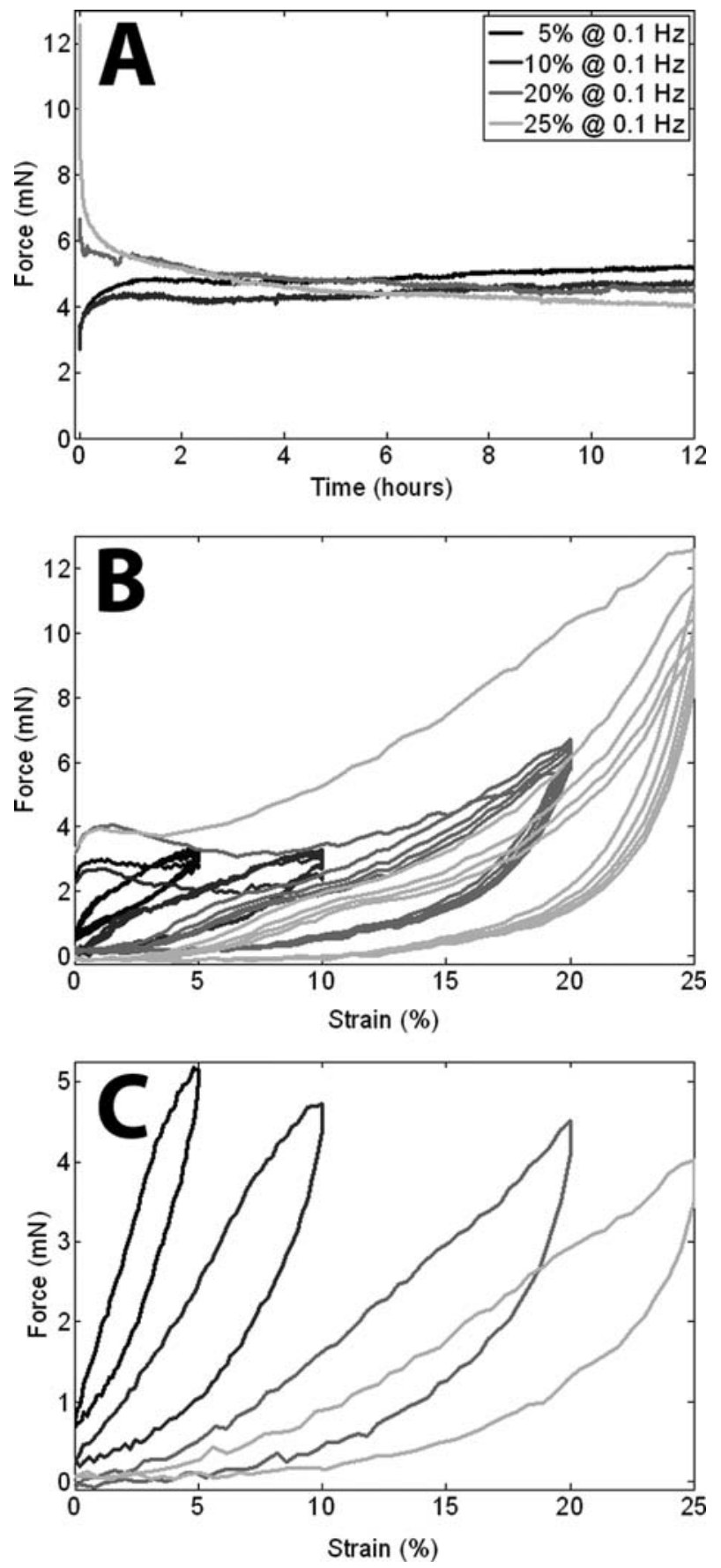

FIGURE 8. Cell force versus cyclic stretch amplitudes after 8 days of static incubation. (A) Peak cell force over $12 \mathrm{~h}$ of cyclic stretch. Peak cell force increased for $5 \%$ and $10 \%$ amplitudes while it decreased for $20 \%$ and $25 \%$ amplitudes. (B) First 5 cell stretches after initiation of cyclic stretch. (C) Last 5 cell stretches after $12 \mathrm{~h}$ of cyclic stretch. The peak cell force and cell stiffness decreased with increased amplitude. The loading curves are nearly linear for all amplitudes.

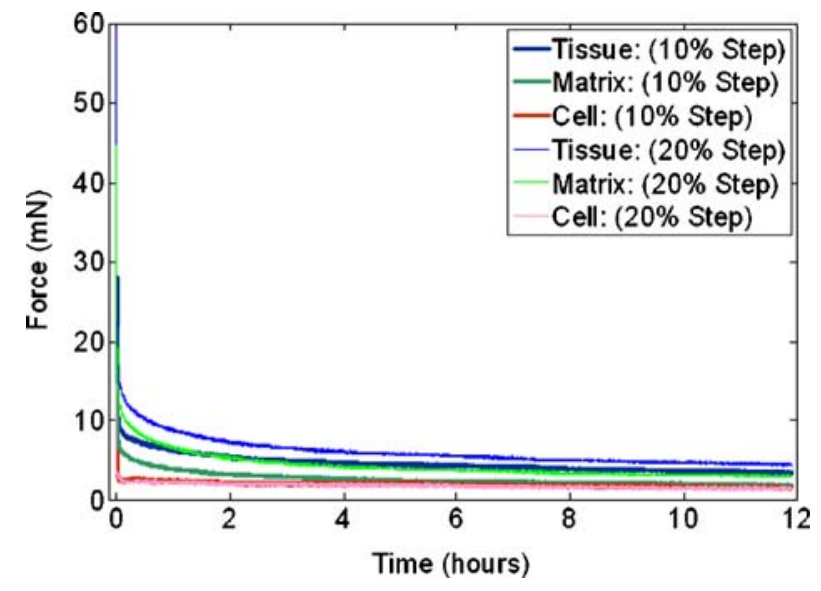

FIGURE 9. Response to step stretch and hold after 8 days of static incubation. The tissue, matrix, and cell forces are shown after a step stretch of either $10 \%$ or $20 \%$. The tissue is held at the stretched length for $\mathbf{1 2} \mathrm{h}$. The tissue and matrix force for a $20 \%$ step and hold is higher than that for a $10 \%$ step and hold. The cell force is identical for $10 \%$ and $20 \%$.

\section{Single Step Stretch \& Hold Effect}

Similar to cyclic stretching at different amplitudes, the larger magnitude step stretches led to higher initial forces (Fig. 9). The tissue force was higher than the matrix force immediately after the step at the same magnitude. However, both tissue and matrix force dropped quickly and to a greater extent for higher magnitudes. The matrix force was lower than the tissue force during the entire $12 \mathrm{~h}$ hold period at the same magnitude indicating that the cells contributed to the measured tissue force throughout the hold period (Fig. 9). The rate of decrease during the $12 \mathrm{~h}$ hold period is similar for both the tissue and matrix. This is evident in the fact that very quickly after the step stretch the cell force approaches a constant for the $12 \mathrm{~h}$ (Fig. 9). The cell force is approximately the same at both $10 \%$ and $20 \%$ step stretches during the $12 \mathrm{~h}$ held at the stretched length. For both step stretch magnitudes, the cell force at the end of the $12 \mathrm{~h}$ hold period is similar to the cell force at the baseline length (data not shown) immediately before the step stretch is applied.

Rings that did not have CytoD added before or during the step stretch were returned to their baseline lengths after being held at the stretched length for $8 \mathrm{~h}$. The force dropped to zero but then began to recover with lower magnitude step stretches increasing their forces faster than higher magnitude step stretches. The recovered forces approached their baseline forces prior to stretch. After $6 \mathrm{~h}$ of monitoring force at baseline, rings stretched to 5\% magnitude and held recovered more of their baseline force $(84 \%)$ than rings stretched to $20 \%$ magnitude ( $42 \%$ ).

The force decreases more rapidly in the step stretch and hold than the peak force drops in cyclic stretching at the same amplitude. 

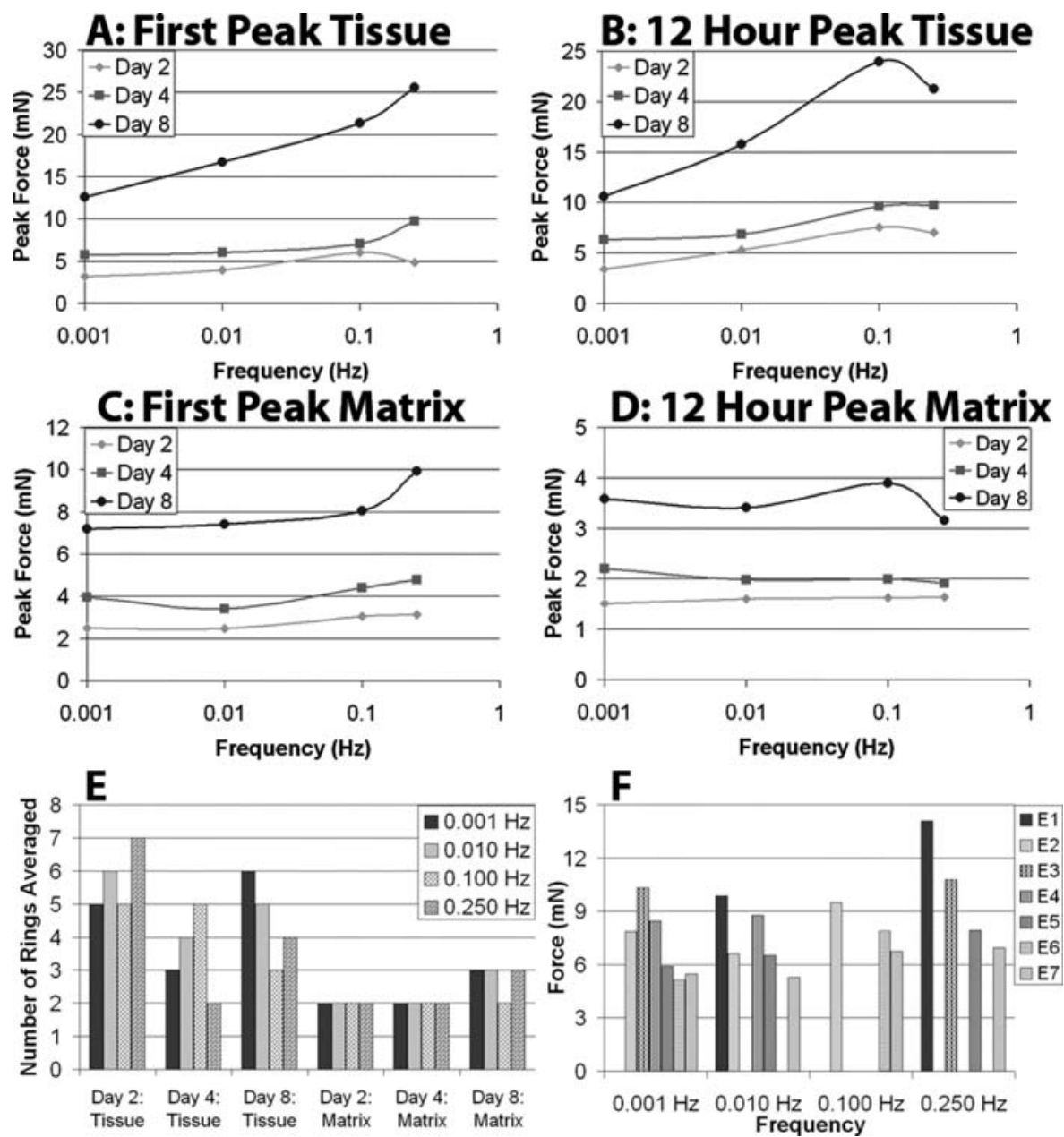

FIGURE 10. Peak tissue and matrix forces for different cyclic stretch frequencies at $10 \%$ amplitude. (A) Peak tissue force of the first cyclic stretch after 2,4 , or 8 days static incubation. Peak tissue force increased with cyclic stretch frequency and incubation time. (B) Peak tissue force after $12 \mathrm{~h}$ of cyclic stretch after 2, 4, or 8 days static incubation. At day 8 the peak tissue force increased slightly with increased frequency. (C) Peak matrix force of the first stretch after 2, 4, or 8 days static incubation. Peak matrix force increased slightly with increased cyclic stretch frequency. (D) Peak matrix force after $12 \mathrm{~h}$ of cyclic stretch after 2 , 4, or 8 days static incubation. Peak matrix force similar regardless of cyclic stretch frequency. (E) Number of rings averaged for data shown in Figs. 10-13 at each frequency and static incubation day. (F) Individual measurements used in panel $B$ [Peak tissue force after $12 \mathrm{~h}$ and 8 days of static incubation]. This shows that the trend within an experiment (E\#) is consistent but the experiment to experiment variation is large. Y-axis scales are different in each panel to emphasize the trends with frequency and incubation time.

\section{Frequency Effect}

Figure 10 illustrates the trends in the peak tissue (Fig. 10(a, b)) and matrix force (Fig. 10(c, d)) either at the first stretch or after $12 \mathrm{~h}$ of cyclic stretch. It also compares the peak force trends over stretch frequencies and static incubation time. At all frequencies the peak tissue and matrix force increased with static incubation (Fig. 10).

\section{Tissue Force}

Initially, higher frequencies led to higher peak tissue forces (Figs. 10(a), 11(a), 11(b)). After an initial drop, the peak force remained steady or increased at days 2 and 4 .
However, at day 8 after the initial drop the peak force continues to decline over the rest of the experiment (Fig. 11(a)). After $12 \mathrm{~h}$, higher frequencies still resulted in higher peak forces (Figs. 10(b), 11(c)). Another difference is in the baseline forces, where lower frequencies had higher baseline forces than high frequencies. Thus, rings cyclically stretched at lower frequencies have lower measured tissue stiffness (slope of the loading curve).

\section{Matrix Force}

Initially, higher frequencies led to higher peak matrix forces (Figs. 10(c), 12(a), 12(b)). These matrix forces quickly dropped over the first few hours and then continued 

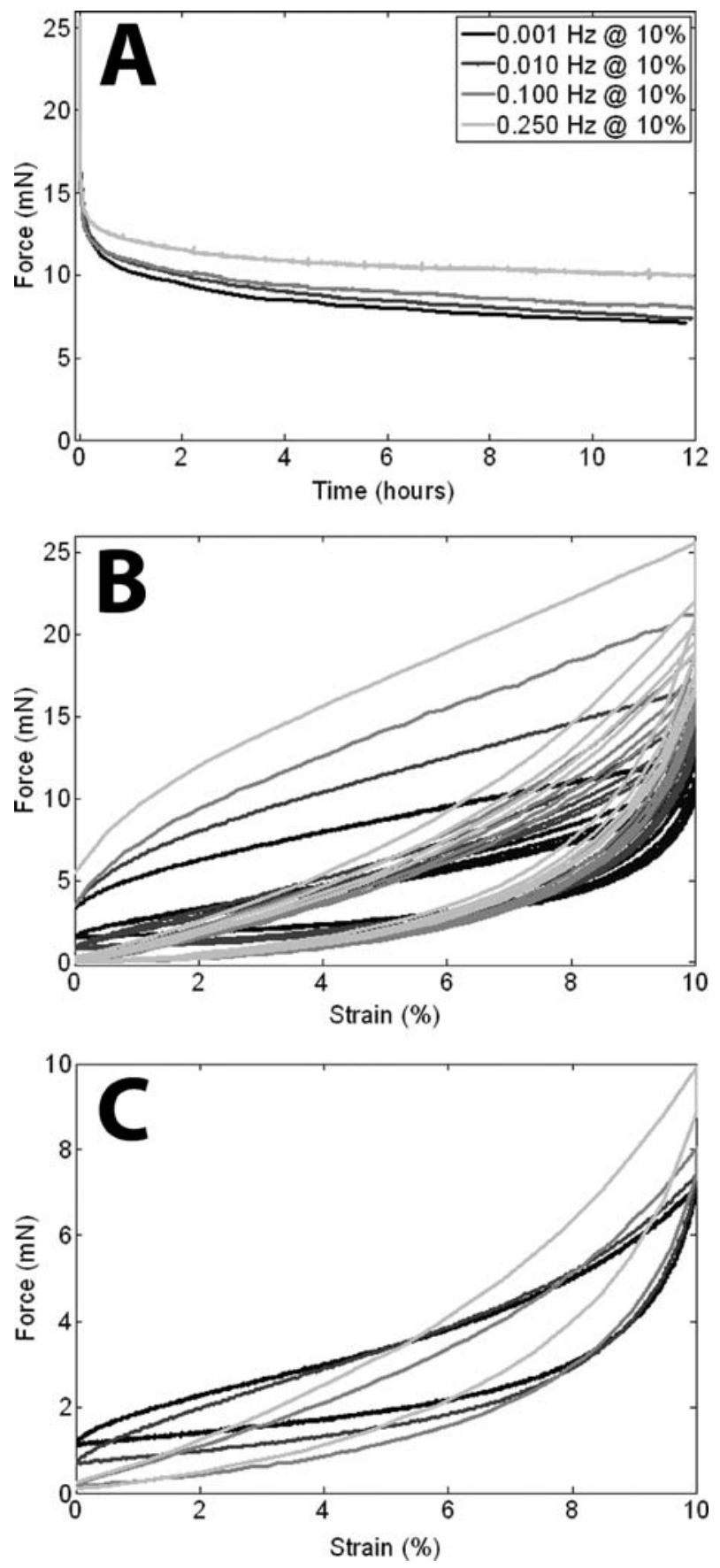

FIGURE 11. Tissue force versus cyclic stretch frequency at day 8. (A) Peak tissue force over $12 \mathrm{~h}$ of cyclic stretch. Peak tissue force dropped quickly after initiation of cyclic stretch followed by a continued slow decline. (B) First 5 tissue stretches after initiation of cyclic stretch. A large decline in tissue force occurred between the first and second stretch. (C) Last 5 tissue stretches after $12 \mathrm{~h}$ of cyclic stretch. The tissue stiffness increased with increasing cyclic frequency.

a steady decline for the remainder of the cyclic stretch (Fig. 12(a)). At day 8, all the peak matrix forces quickly approached the same value about $30 \mathrm{~min}$ after the start of stretch (Fig. 12(a)). In addition, unlike the tissue and cell curves, there is little difference between the matrix curves at the different frequencies after $12 \mathrm{~h}$ except that lower frequencies contribute over a slightly larger range of strains but the peak force is still the same at all frequencies tested (Fig. 12(c)). As with the matrix force at different amplitudes, the loading curve was nonlinear and the matrix contributed only to the tissue force when the strain was within $4-6 \%$ of its maximum value.

\section{Cell Force}

Similar to the first force-strain curves at different amplitudes, the cell force initially rose, then leveled off or even decreased at the highest frequency (Fig. 13(b)). At lower frequencies the slope of the loading curve was lower than that for higher frequencies (Fig. 13(c)). This is clear at day 8 when, for low frequency, the baseline cell force was higher and the peak cell force was lower than that of high frequencies (Fig. 13(c)). At the two lowest frequencies the cells were able to maintain a baseline force while at the two highest frequencies the baseline cell force was near zero. This leads to a cell stiffness that was higher at higher cyclic stretch frequencies. This was similar to the trend seen with the tissue stiffness.

\section{Immunohistochemistry}

Rings stained with a dye for actin cytoskeleton showed a distinct morphology that developed during the 8 days of incubation. Initially the cells were sparse with few cells on the outer layer of the rings (Fig. 14(a)). The inner core of the rings initially showed a higher cell concentration that had some alignment along the circumferential direction (Fig. 14(b)). As the rings incubated, this outer layer that was approximately $25 \mu \mathrm{m}$ thick increased in density but showed little preferential alignment (Fig. 14(c,e)). The inner core of the rings also had some increase in cell density but was noticeably less dense than the outer layer (Fig. 14(d,f)). However, these cells were highly aligned in the circumferential direction (Fig. 14(d,f)).

\section{DISCUSSION}

We have shown that a few hours after the initiation of stretch, higher cyclic stretch amplitude does not lead to higher cell or tissue forces. Thus, for the majority of the cyclic stretch duration, the peak stress experienced by the cells is independent of the stretch amplitude applied, at least in the range of $5 \%-25 \%$. This is accomplished by the cells becoming less stiff at higher stretch amplitudes. The exact mechanism for this change in cell stiffness is unknown. We have found that the magnitude of the drop in tissue force after the addition of $2 \mu \mathrm{m}$ CytoD is similar to the force drop after adding detergent (e.g. deoxycholate). Since the detergent treatment actually removes the cells, ${ }^{18}$ it is likely the actin cytoskeleton is primarily responsible for the change 

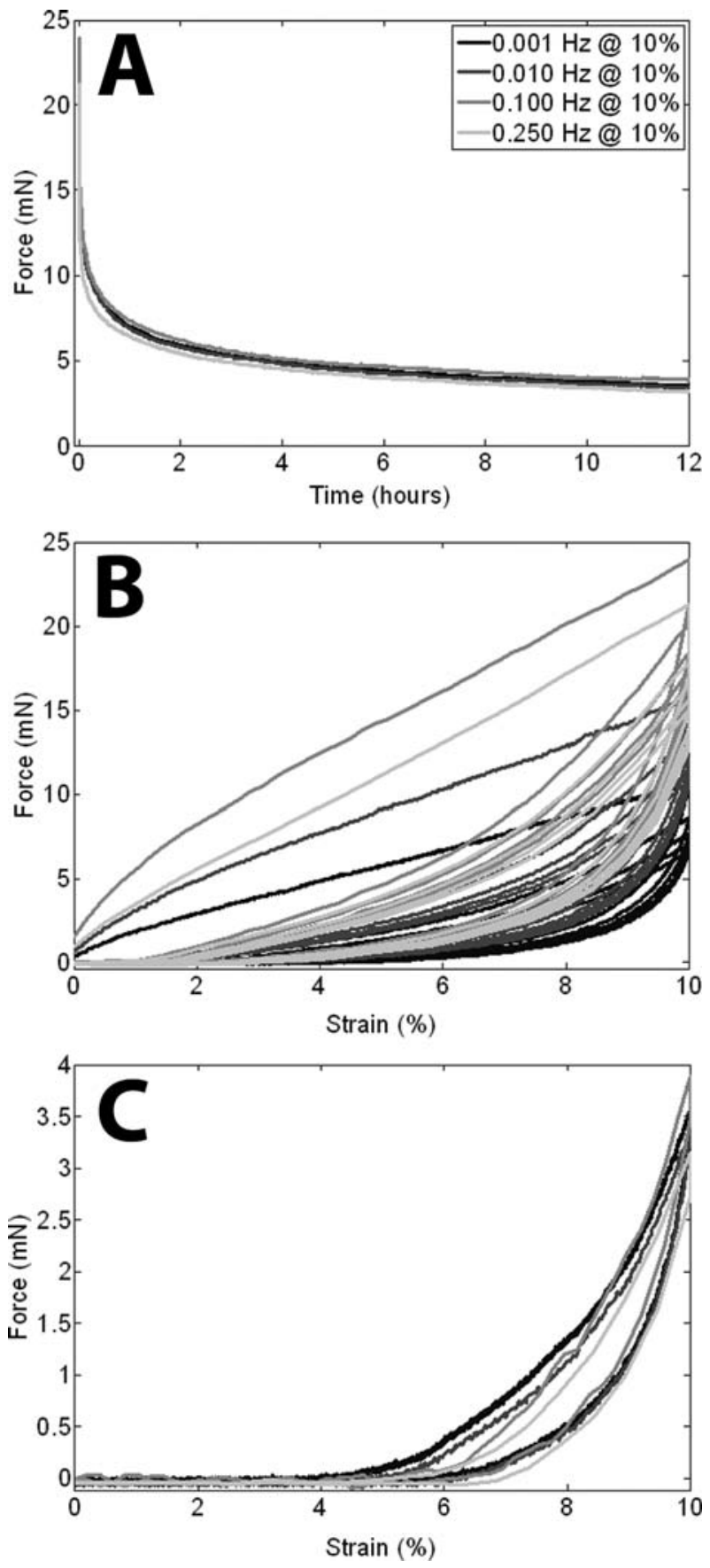

FIGURE 12. Matrix force versus cyclic stretch frequency at day 8. (A) Peak matrix force over $12 \mathrm{~h}$ of cyclic stretch. Peak matrix force dropped quickly after initiation of cyclic stretch followed by a slow decline for the 12 h duration. (B) First 5 matrix stretches after initiation of cyclic stretch. A large decline in matrix force occurred between the first and second stretch. (C) Last 5 matrix stretches after $12 \mathrm{~h}$ of cyclic stretch. Matrix loading curves were highly nonlinear and the peak forces was similar at all frequencies.

in cell stiffness. Whether this is a result of cytoskeletal remodeling and/or reduction in active contraction/relaxation of the myosin is not known.
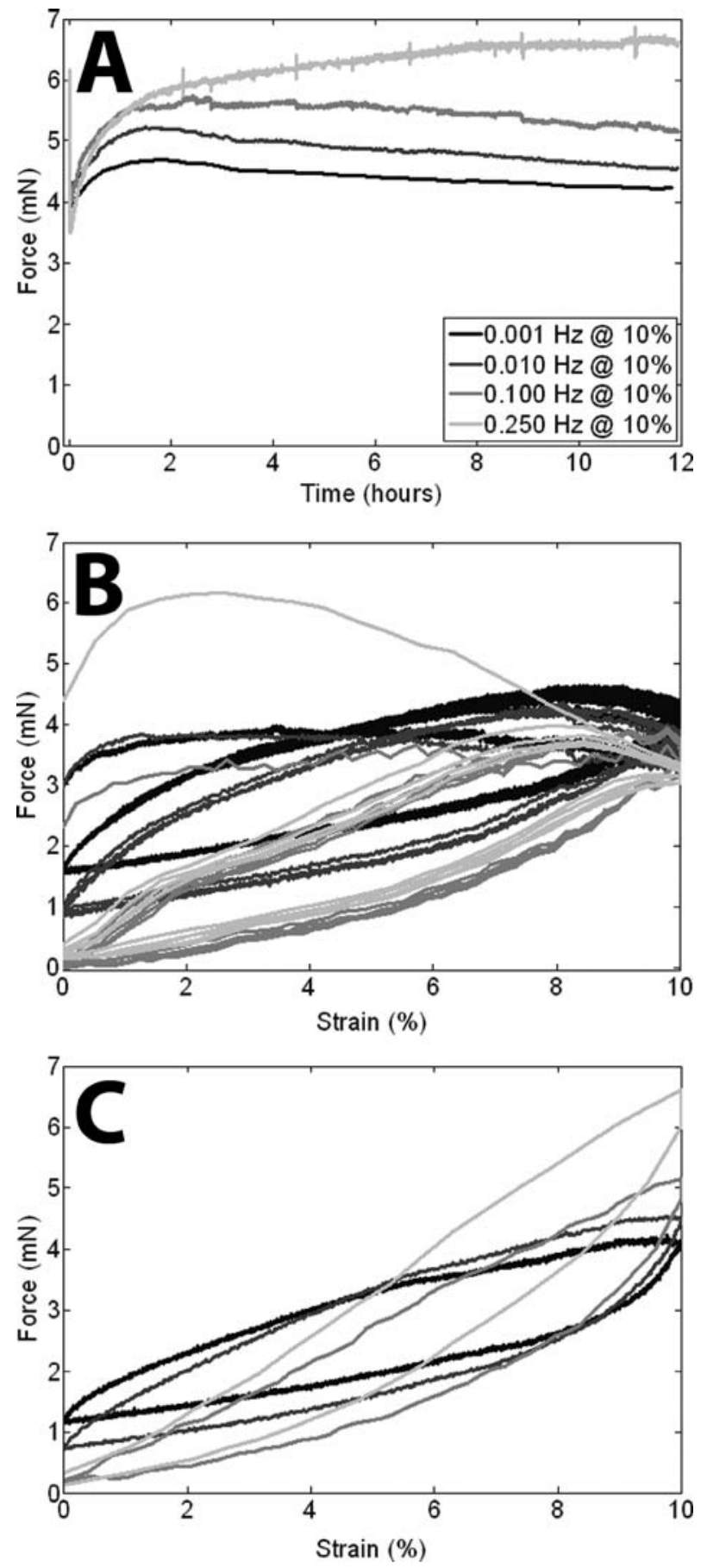

FIGURE 13. Cell force versus cyclic stretch frequencies at day 8. (A) Peak cell force over $12 \mathrm{~h}$ of cyclic stretch. (B) First 5 cell stretches after initiation of cyclic stretch. (C) Last 5 cell stretches after $12 \mathrm{~h}$ of cyclic stretch. Cell stiffness increased with increasing cyclic stretch frequency.

While the initial extracellular matrix consists entirely of collagen it is reasonable to assume that over 8 days of incubation time that additional cell-contributed matrix may be produced. We have incubated rings for 20 days prior to cyclic stretching and found that the matrix force-strain curves are similar to those after 8 days of incubation. Peak 

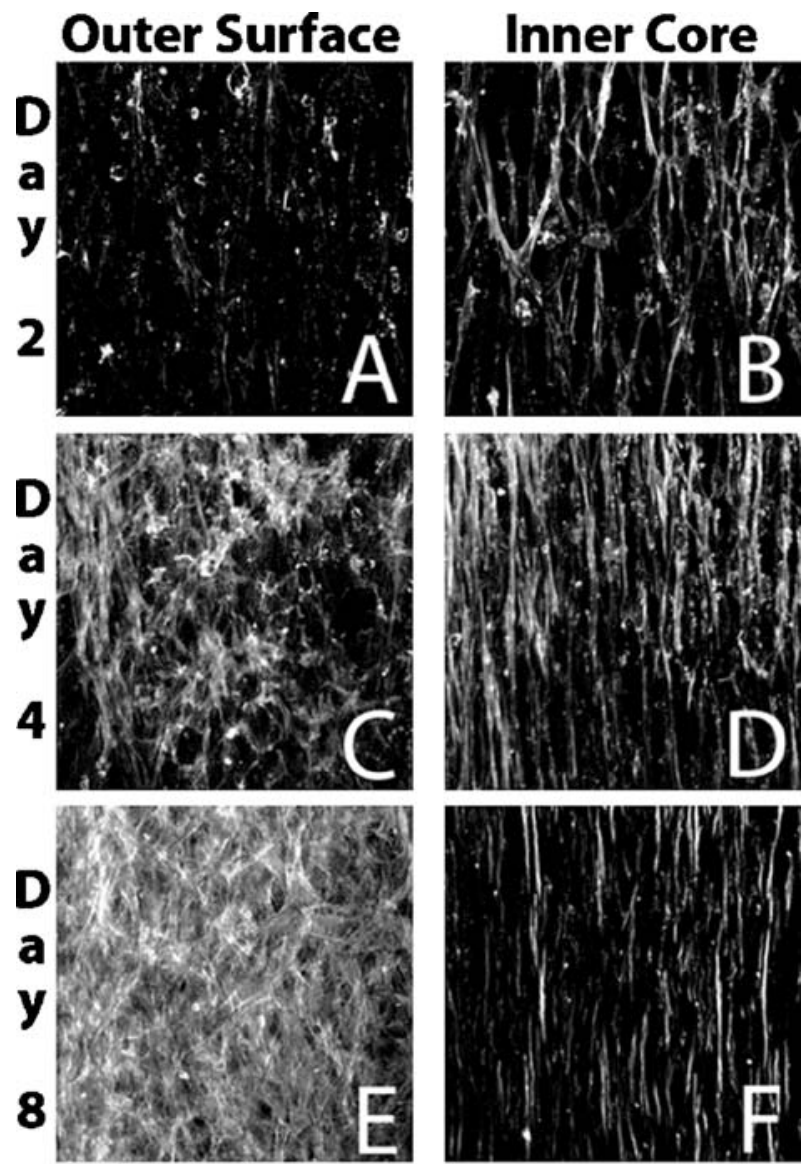

FIGURE 14. Confocal images at 2, 4, and 8 days of static incubation. F-actin fibers visualized using a TRITC phalloidin stain. (A) Outer surface (projection from 4-14 $\mu \mathrm{m}$ depth) after 2 days static incubation. (B) Inner core (projection from 150$160 \mu \mathrm{m}$ depth) after 2 days static incubation. (C) Outer surface (projection from 4-14 $\mu \mathrm{m}$ depth) after 4 days static incubation. (D) Inner core (projection from 61-71 $\mu \mathrm{m}$ depth) after 4 days static incubation. (E) Outer surface (projection from 10-15 $\mu \mathrm{m}$ depth) after 8 days static incubation. $(F)$ Inner core (projection from $60-65 \mu \mathrm{m}$ depth) after 8 days static incubation. Field of View: $230 \mu \mathrm{m} \times 230 \mu \mathrm{m}$. Circumferential direction is in the vertical direction.

forces increase only a small amount at $5 \%$ or $10 \%$ stretch amplitude after $14 \mathrm{~h}$ of cyclic stretch at $0.1 \mathrm{~Hz}$. These results suggest that the matrix mechanics do not change substantially even in the presence of cells that can produce additional matrix.

In addition, we treated some rings with $30 \mathrm{mM}$ ribose after 10 days of incubation, and incubated them for an additional 10 days to non-enzymatically crosslink the collagen. ${ }^{9}$ This treatment increased the peak matrix force during cyclic stretch with a 3 to 4 fold increase after $14 \mathrm{~h}$ compared to the untreated rings incubated for 20 days. The shapes of the matrix force-strain curves changed somewhat, with a shorter period of slack during each force-strain curve. The increased peak force with glycation was similar to Isenberg and Tranquillo 9 but comparing the shapes of the forcestrain curves is difficult due to differences in experimental methods.

We also found that increased matrix stiffness due to crosslinking had little effect on cell force for $5 \%$ or $10 \%$ cyclic stretch amplitude at $0.1 \mathrm{~Hz}$. Cell force-strain curves were almost identical for treated and untreated rings after $12 \mathrm{~h}$ of cyclic stretch. In 2-D cultures, cell traction depends upon the stiffness of the substrate. ${ }^{6}$ The cellular mechanism for this response is not clear, but Discher and co-workers suggest that both "outside-in" and "inside-outside-in" pathways may be involved. Whether 3-D culture conditions or cyclic stretching reduce the influence of matrix stiffness on cellular mechanics remains to be investigated.

Since it is the cells that are responding to the mechanical conditioning it is important to realize that while the cells are undergoing a higher strain they are not undergoing a higher stress. So if the cells respond to stress, higher stretch amplitudes will not increase this response. Since both the cells and the tissues at different stretch amplitudes maintain similar stresses, it is reasonable to assume the cells are responding to maintain a certain range of mechanical stresses.

Some limitations to estimating the cell-contributed force should be noted. Unlike the tissue and matrix force we are not able to measure the cell force directly but instead have to estimate it based on the direct measurement of the tissue and matrix. In addition, to estimate the cell force at more than a single time point, we must use the forces from different rings. Due to the ring to ring variations, it is necessary to normalize one ring to another to get quantitative values for the cell force. However, because this normalization occurs at $12 \mathrm{~h}$, it is unknown how well this single point normalization works in predicting the cell force $12 \mathrm{~h}$ earlier during the initial stretches. Furthermore, the assumption that the cell force is simply the subtraction of the matrix force from the tissue force is only valid after a critical cell density is reached. ${ }^{11}$ At days 2 and 4 it is unlikely that this critical cell density is reached but it is surpassed based on cell density by day 8 .

Unlike the cells that respond to increased stretch amplitude by decreasing their stiffness, the matrix force-strain curves shift so that the matrix contributes only when the strain is within $3 \%-7 \%$ of the maximum value with the matrix contributing over a slightly larger range of strains at higher stretch amplitudes. This response of the matrix does not appear to depend upon the cells having an actin cytoskeleton, since we found a similar response when cytoD is added either before stretch is initiated or after $12 \mathrm{~h}$ of stretch. After $12 \mathrm{~h}$ of cyclic stretch, the peak matrix force is only slightly higher with increased stretch amplitude. With different frequencies of cyclic stretch, the peak matrix force is similar but the matrix contributes over a larger range of strains at lower frequencies. For a $10 \%$ stretch, the matrix contributes to the last $6 \%$ of the 
stretch at $0.001 \mathrm{~Hz}$ while contributing only to the last $4 \%$ at $0.25 \mathrm{~Hz}$.

The higher baseline tissue and cell forces seen at lower frequencies $(0.001 \mathrm{~Hz}$ and $0.01 \mathrm{~Hz})$ are consistent with a simple viscoelastic model because the tissues and cells have more time to recover before being stretched again. The same is seen in the lower amplitudes at $0.1 \mathrm{~Hz}(5 \%$ and $10 \%$ ) which are able to maintain a baseline force. These correspond to the lowest strain rates and may allow for recovery.

For a linear viscoelastic material undergoing continuous cyclic stretch, both higher stretch amplitudes and higher strain rates will lead to higher peak forces. For cyclic stretch at constant frequency, the highest stretch amplitude also corresponds to the highest strain rate. However, we observed that the peak cell force decreased as the amplitude (and the strain rate) increased. We also note that the decrease in peak cell force is a function of both stretch amplitude and strain rate because similar strain rates $(5 \% / \mathrm{s})$ at different amplitudes (e.g. 10\%@0.25 Hz and 25\% @ $0.1 \mathrm{~Hz}$ ) show different tissue, matrix and cell responses In the case of the matrix at $25 \% @ 0.1 \mathrm{~Hz}$, there is no positive matrix force until the strain increases beyond 10\%; whereas there is matrix force below $10 \%$ strain during cyclic stretch at $10 \% @ 0.25 \mathrm{~Hz}$.

To explain this complex behavior a model of cellular mechanics that includes strain-dependent and strain ratedependent damage may be required. It is reasonable to assume large and/or quick deformations may result in disruption of the actin cytoskeleton ${ }^{8}$ leading to damage, and thus a reduction in the cell force and stiffness. However, any damage model will be complicated by viscoelastic effects.

One possible mechanism for a strain dependent change in stiffness is an alteration in the amount of cell activation through a stretch-activated pathway. Two of the pathways that exist to activate myosin-light chain kinase and thus force generation in fibroblasts are a calcium dependent pathway and a Rho dependent pathway. ${ }^{13}$ To test the possible involvement of a calcium dependent pathway, we tested some rings in the presence of $50 \mu \mathrm{M}$ or $500 \mu \mathrm{M}$ of gadolinium chloride $\left(\mathrm{GdCl}_{3}\right)$ to block stretch activated calcium channels. ${ }^{12}$ In the presence of $50 \mu \mathrm{M}$ of $\mathrm{GdCl}_{3}$, day 2 rings showed a decrease in peak tissue force at both $5 \%$ and $10 \%$ cyclic stretch compared to untreated controls. This peak force decrease continued for the first 5-6 h of cyclic stretch then began to increase for the remainder of the $12 \mathrm{~h}$ of cyclic stretching but still did not return to the peak tissue force of untreated controls. However, for day 8 rings neither 50 nor $500 \mu \mathrm{M} \mathrm{GdCl}_{3}$ had an effect on the tissue force compared to untreated controls. Since $\mathrm{GdCl}_{3}$ reduces the tissue and cell force during the first several hours of cyclic stretch at day 2, it suggests that the calcium dependent pathway plays a role in maintenance of cell force at least during early tissue development. It is unclear what causes the cell force to increase after the initial decrease but it could be due to an upregulation of calcium independent pathways or incomplete inhibition of new or existing stretch activated channels. The lack of an effect of $\mathrm{GdCl}_{3}$ at day 8 suggests a reduced role of the calcium dependent pathway.

In addition, these results have important implications for the tissue engineering field, especially for those tissues that undergo continuous deformations such as in the cardiovascular system. By isolating the cell contribution to tissue force, we are able to provide a better understanding of the mechanical environment of the cell and aid in designing mechanical conditioning protocols that improve tissue properties. For example, the peak cell force is not constant during cyclic stretch and thus cell stimulation varies with time. Furthermore, if cell response is dependent on cell stress or force, increasing the amplitude of conditioning will not increase and may decrease the applied cell force.

Due to the large changes in mechanical behavior after initiation of cyclic stretch, it is important to characterize engineered tissues' response to these loading conditions over longer time periods. Current mechanical characterization relies mostly on a few cycles of preconditioning followed by a test to failure. ${ }^{4,5,9,16}$ While failure tests are necessary, the response of the tissue and cells under physiologic loading is also vital. We have shown that mechanical properties may change dramatically over hours after initiation of stretch. These changes have implications on tissue function in vivo after implantation and these changes cannot be captured in simple failure tests.

\section{CONCLUSIONS}

We have shown that bioartificial tissue constructs consisting of a single cell type and matrix component are a useful model system in which to explore tissue, matrix, and cell mechanics. The cell response to cyclic stretch is complex and depends on both the amplitude and frequency of cyclic stretch. The change in cell stiffness with amplitude behavior does not fit current cellular mechanics models. Future investigations may explore the microstructural basis for this behavior.

\section{ACKNOWLEDGMENTS}

Jeremiah Wille was supported by a Whitaker Foundation Graduate Research Fellowship. This work was supported in part by the National Institutes of Health grant AR47591 (Elson).

\section{REFERENCES}

${ }^{1}$ Arts, T., T. Delhaas, P. Bovendeerd, X. Verbeek, and F. W. Prinzen. Adaptation to mechanical load determines shape and properties of heart and circulation: The CircAdapt model. Am. J. Physiol. Heart. Circ. Physiol. 288:H1943-H1954, 2005. 
${ }^{2}$ Berry, C. C., C. Cacou, D. A. Lee, D. L. Bader, and J. C. Shelton. Dermal fibroblasts respond to mechanical conditioning in a strain profile dependent manner. Biorheology 40:337-345, 2003.

${ }^{3}$ Berry, C. C., J. C. Shelton, D. L. Bader, and D. A. Lee. Influence of external uniaxial cyclic strain on oriented fibroblast-seeded collagen gels. Tissue Eng. 9:613-624, 2003.

${ }^{4}$ Billiar, K. L., A. M. Throm, and M. T. Frey. Biaxial failure properties of planar living tissue equivalents. J Biomed. Mater Res. A. 73A:182-191, 2005.

${ }^{5}$ Cummings, C. L., D. Gawlitta, R. M. Nerem, and J. P. Stegemann. Properties of engineered vascular constructs made from collagen, fibrin, and collagen-fibrin mixtures. Biomaterials 25:3699-3706, 2004.

${ }^{6}$ Discher, D. E., P. Janmey, and Y. L. Wang. Tissue cells feel and respond to the stiffness of their substrate. Science 310:11391143, 2005.

${ }^{7}$ Eghbali, M. Cardiac fibroblasts: function, regulation of gene expression, and phenotypic modulation. Basic Res. Cardiol. 87(Suppl 2):183-189, 1992.

${ }^{8}$ Goldman, J., L. Zhong, and S. Q. Liu. Degradation of alpha-actin filaments in venous smooth muscle cells in response to mechanical stretch. Am. J. Physiol. Heart Circ. Physiol. 284:H18391847, 2003.

${ }^{9}$ Isenberg, B. C., and R. T. Tranquillo. Long-term cyclic distention enhances the mechanical properties of collagen-based media-equivalents. Ann. Biomed. Eng. 31:937-949, 2003.

${ }^{10}$ Krishnan, L., J. A. Weiss, M. D. Wessman, and J. B. Hoying. Design and application of a test system for viscoelastic characterization of collagen gels. Tissue Eng. 10:241-252, 2004.

${ }^{11}$ Marquez, J. P., G. M. Genin, G. I. Zahalak, and E. L. Elson. The relationship between cell and tissue strain in three-dimensional bio-artificial tissues. Biophys. J. 88:778-789, 2005.
${ }^{12}$ Munevar, S., Y. L. Wang, and M. Dembo. Regulation of mechanical interactions between fibroblasts and the substratum by stretch-activated Ca2 + entry. J. Cell Sci. 117:85-92, 2004.

${ }^{13}$ Parizi, M., E. W. Howard, and J. J. Tomasek. Regulation of LPApromoted myofibroblast contraction: role of Rho, myosin light chain kinase, and myosin light chain phosphatase. Exp. Cell Res. 254:210-220, 2000.

${ }^{14}$ Prior, B. M., H. T. Yang, and R. L. Terjung. What makes vessels grow with exercise training? J. Appl. Physiol. 97:1119-1128, 2004.

${ }^{15}$ Seliktar, D., R. A. Black, R. P. Vito, and R. M. Nerem. Dynamic mechanical conditioning of collagen-gel blood vessel constructs induces remodeling in vitro. Ann. Biomed. Eng. 28:351-362, 2000.

${ }^{16}$ Seliktar, D., R. M. Nerem, and Z. S. Galis. Mechanical strainstimulated remodeling of tissue-engineered blood vessel constructs. Tissue Eng. 9:657-666, 2003.

${ }^{17}$ Stegemann, J. P., and R. M. Nerem. Phenotype modulation in vascular tissue engineering using biochemical and mechanical stimulation. Ann Biomed. Eng. 31:391-402, 2003.

${ }^{18}$ Wagenseil, J. E., Mechanical Properties of Fibroblast Populated Collagen Matrices. D.Sc. Thesis, Dept. of Biomedical Engineering, Washington University, 2003.

${ }^{19}$ Wagenseil, J. E., T. Wakatsuki, R. J. Okamoto, G. I. Zahalak, and E. L. Elson. One-Dimensional Viscoelastic Behavior of Fibroblast Populated Collagen Matrices. J. Biomech. Eng. 125:719-725, 2003.

${ }^{20}$ Wakatsuki, T., M. S. Kolodney, G. I. Zahalak, and E. L. Elson. Cell mechanics studied by a reconstituted model tissue. Biophys. J. 79:2353-2368, 2000.

${ }^{21}$ Wakatsuki, T., B. Schwab, N. C. Thompson, and E. L. Elson. Effects of cytochalasin D and latrunculin B on mechanical properties of cells. J Cell Sci. 114:1025-1036, 2001. 